\title{
A kind of special weld lines with high specific strength and elongation obtained by core-back chemical foam injection molding
}

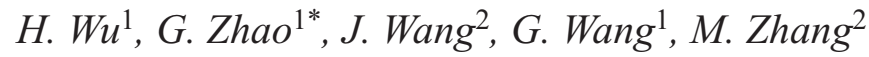 \\ ${ }^{1}$ Key Laboratory for Liquid-Solid Structural Evolution and Processing of Materials (Ministry of Education), Shandong \\ University, Jinan, 250061 Shandong, PR China \\ ${ }^{2}$ Qingdao Hisense Mould Co., Ltd. Qingdao, 266114 Shandong, PR China
}

Received 17 April 2019; accepted in revised form 18 June 2019

\begin{abstract}
In this paper, a kind of polypropylene (PP) foam plastic parts with special weld lines were obtained by core-back foam injection molding with chemical blowing agent. A new kind of weld line was found and its formation process was proposed. The unique principle of the weld lines formation in core-back foam injection molding process was revealed. The surface and internal morphologies, fracture morphologies, cell structure, and mechanical properties of the weld line area of the specimens respectively obtained by core-back foam injection molding and conventional foam injection molding were compared and analyzed. The mechanism of core-back foam injection molding in improving the mechanical properties of the weld line was clarified. The results show that the specimens with special weld lines not only have relatively uniform inner cell structure in size and distribution, but also have a special reticular structure in the weld line area. This reticular structure can not only play a role similar to fiber reinforcement itself, but also increases the bonding degree of polymer at weld lines. Under the action of this special weld line structure, the tensile strength and elongation at break of the specimen are significantly improved, and the weight reduction effect is much better under the premise of ensuring certain mechanical properties.
\end{abstract}

Keywords: mechanical properties, core-back, injection molding, polypropylene, weld lines

\section{Introduction}

With the rapid development of modern civilization, problems such as large consumption of resources and environmental pollution seriously restrict the development of manufacturing industry. Energy saving, emission reduction and sustainable development have become the most important issues in today's manufacturing industry. As a kind of lightweight materials, foamed polymer materials with high porosity can not only reduce the raw material consumption, product assembling weight, energy consumption, emissions and environmental pollution, but also have excellent thermal and sound insulation properties, low dielectric constant, and excellent energy absorption capacity.
Therefore, they have broad application prospects in thermal insulation, sound insulation, noise reduction, energy saving, and emission reduction [1].

Foam injection molding is one of the common methods of polymer foam molding. This method has good versatility and is suitable for foaming of most thermoplastic polymer materials. In addition, it has short production cycle, high yield, and high production efficiency [2-4]. In the process of the conventional foam injection molding, due to the restriction of mold cavity, the space needed for the growth of cells in polymer melt after nucleation mainly depends on the cooling shrinkage of polymer or short shot. However, the shrinkage of crystalline polymers is $1.0-3.0 \%$ 
and amorphous polymers are only $0.4-0.8 \%$ during cooling and solidification. Therefore, it is very limited that the cooling shrinkage of polymer solution provides space for the growth of foams after nucleation. In addition, short shot will cause uneven distribution of cell size and cell density at near gate end and far gate end, which seriously affects the mechanical properties of plastic parts.

Core-back foam injection molding [5-16] provides space for the growth of cells in polymer melt after nucleation by opening the mold or withdrawing the core of the mold at a certain distance. By using this method, sufficient space can be provided for the growth of cells after nucleation in the foam injection molding process, so as to improve the foam ratio and the uniformity of the cell size and distribution in the foamed plastic parts [17-19]. Wang et al. [20] obtained PLA/graphite nanocomposites with cell size of $12 \mu \mathrm{m}$ and cell density of $1.8 \cdot 10^{8}$ cell $/ \mathrm{m}^{3}$ by coreback foaming injection molding. Shaayegan et al. [21] obtained PS foams with cell size of $35 \mu \mathrm{m}$ and cell density of $10^{7}$ cell $/ \mathrm{m}^{3}$ by core-back foam injection molding. In our previous studies, PP foams with special skin structure with an average cell size of $46 \mu \mathrm{m}$ and cell density of $1.8 \cdot 10^{6}$ cell $/ \mathrm{m}^{3}$ were obtained by using a new core-back foam injection process with chemical blowing agent. The weight reduction effect of this PP foamed parts was obvious, and the surface quality and mechanical properties were better than those of the conventional foam injection molding parts under the same parameters [22].

However, no matter using conventional foam injection molding or core-back foam injection molding, when there are two or more gates in the mold, or when the mold cavity is complex and has a divergent design, there will be an unavoidable defect - weld lines. Weld lines are formed when two or more polymer melt flow fronts meet and merge together when polymer melt fills the cavity during injection molding, or when polymer melt encounters obstacles in the process of flow, one flow front of original polymer melt is divided into two or more flow fronts by obstacles, and merges together behind the obstacles to form weld lines [23]. During the formation of weld lines, a layer of 'skin' is formed by premature cooling and solidification of the melt flow front. When melt flow fronts with such 'skin' meet each other and form weld lines, the actual contact part is the 'skin' of the melt flow fronts which have been cooled in some degree and partially solidified, even there may be a portion of the air encapsulated between the contact surfaces. This kind of weld lines greatly reduce the strength of polymer melt joints and seriously affect the mechanical properties of plastic parts [24, 25]. In order to understand the influence of weld lines on the mechanical properties of plastic parts and reduce their adverse influence, researchers have done a lot of research through experiments or simulation methods. Carneiro et al. [25] simulated and analyzed the flow behavior of polymer melt in extrusion die with splitter bridge during the weld line formation process and studied the flow type of melt and corresponding stress of splitter bridge position by using Giesekus model and the extended version of OpenFOAM under the assumption of isothermal flow of polymer melt during the whole weld line formation process. The results showed that higher temperature and pressure can improve the mechanical properties of extruded polymers with weld lines. Kitayama et al. [26] studied the relationship between melt temperature and pressure during the weld line formation and their influence on the strength of weld lines by numerical simulation and experiments. The results showed that there is a compromise relationship between melt temperature and pressure during the weld line formation when the strength of weld line is constant. In addition, with the use of follow-up cooling channel, the melt temperature and pressure during the weld line formation can be lowered to the greatest extent under the premise of guaranteeing the mechanical properties of products. By using digital image correlation (DIC) method, Kalus et al. [27] studied the local small-size mechanical properties of weld lines in fiber reinforced and non-fiber-reinforced polyamide materials obtained by injection molding. The results showed that the fibers themselves do not enhance the mechanical properties of the weld lines directly, but enhance the mechanical properties of the weld lines by reducing the Poisson shrinkage and necking at the weld lines. Minh et al. [28] studied the weld line strength of $40 \%$ talc filled PP injection molding parts by combining tensile stress-strain behavior with fracture mechanics. The results showed that the yield strength, yield strain and failure strain of talc filled PP plastic parts with weld lines increase with the increase of melt temperature and holding pressure. In most cases, higher polymer melt temperature and pressure are helpful to improve the mechanical properties of plastic parts with weld lines $[25,26,28-30]$. 
For injection molding parts with complex structure, weld lines are inevitable. The mechanical properties of weld lines are the key factors affecting the properties of plastic parts. Especially in the field of lightweight, how to increase the weight reduction of plastic parts while ensuring that the mechanical properties of weld lines meet or exceed the required use standards has been a very concerned issue in the industry. Although researchers have done a lot of research on the factors affecting the mechanical properties of the weld lines and have given many schemes to improve their mechanical properties, most of these schemes are based on the conventional structure of the weld lines and ultimately do not change the structure of the weld lines, which limits the further improvement of the mechanical properties of plastic parts with weld lines. Therefore, it is of great significance to study how to change the conventional structure of the weld line and further improve the mechanical properties of the plastic parts with weld lines.

In this paper, PP plastic parts with a kind of special weld lines were obtained by using core-back foam injection molding method and chemical blowing agent AC. Compared with the weld lines of plastic parts obtained by the conventional foam injection molding, this special weld lines have special formation process and special structure. Firstly, under the action of the special skin structure formed by coreback foam injection molding [22], polymer melts can maintain a higher temperature when they meet, so are better bonded together. Secondly, in the process of core-back, the unique skin structure of the weld line area is stretched into a reticular structure, which plays a role similar to fiber reinforcement to a certain extent. In addition, this reticular structure can also induce cross-flow and intertwining of newly injected polymer melts in the region, which makes a better bonding of polymer at the weld lines. Compared with the conventional foam injection molding parts with weld lines, this kind of parts with special weld lines have better weight reduction, higher tensile strength and larger elongation at break. The tensile strength, specific tensile strength and elongation at break were increased by $30.7,53.3$ and $550 \%$, respectively.

\section{Experiments and characterization tests 2.1. Experiments design}

In this paper, core-back chemical foam injection molding experiments and conventional chemical foam injection molding experiments were carried out respectively, and the results of the two kinds of molding experiments were compared. In order to ensure the comparability of the results, the same foam process parameters shown in Table 1 were used. It should be noticed that the core-back distance, core-back time, and core-back rate are the unique parameters for coreback chemical foam injection molding, while the other parameters are the same for the two kinds of injection molding. The experiment material is syndiotactic PP (BJ550), which was provided by Samsung Total, Korea. Azodicarbonamide (AC) was used as the blowing agent for experiments, its decomposition temperature is $195-210^{\circ} \mathrm{C}$, gas volume is 190 $240 \mathrm{ml} / \mathrm{g}$. A double shaft blade mixer was used to mix the AC blowing agent and polypropylene, and a 180 ton pure electric injection molding machine (J180ADC180H, Japan Steel Work, Ltd) was used as the injection molding machine. A new type of experimental core-back FIM mold shown in Figure 1a$1 \mathrm{c}$ was used in this paper. The gates of the mold are edge gates. In addition, the gates are both $7 \mathrm{~mm}$ in length and $1 \mathrm{~mm}$ in width. The cavity depth control structure shown in Figure 1d is the core structure of the mold. With this structure, each cavity of the mold can do core-back independently. Mechanical coordination structure shown in Figure 1e is the basic structure of the cavity depth control structure. Figure $1 \mathrm{f}$ and $g$ give the operation principle of the mechanical coordination structure. In the initial state shown in Figure 1f, the piston rod of the hydraulic cylinder is in a short protruding state, the tip of the piston rod is connected to the chute, the sliding block is in the initial position, and the depth of the cavity is the minimum at this time. When the hydraulic cylinder begins to work, the piston rod extends outward and pushes the chute moving along the blue arrow shown in Figure 1f. At this moment, because

Table 1. Technological parameters of foam injection molding experiment.

\begin{tabular}{|ll|l|}
\hline \multicolumn{2}{|c|}{ Parameters } & Values \\
\hline AC content & {$[\mathrm{wt} \%]$} & 7 \\
\hline Mold temperature & {$\left[{ }^{\circ} \mathrm{C}\right]$} & 50 \\
\hline Shot size & {$\left[\mathrm{cm}^{3}\right]$} & 31 \\
\hline Injection speed & {$\left[\mathrm{cm}^{3} / \mathrm{s}\right]$} & 130 \\
\hline First stage holding pressure & {$[\mathrm{MPa}]$} & 10 \\
\hline First stage holding time & {$[\mathrm{s}]$} & 2 \\
\hline Second stage holding pressure & {$[\mathrm{MPa}]$} & 8 \\
\hline Second stage holding time & {$[\mathrm{s}]$} & 0.5 \\
\hline Core-back rate & {$[\mathrm{mm} / \mathrm{s}]$} & 7 \\
\hline Core-back distance & {$[\mathrm{mm}]$} & 3.5 \\
\hline
\end{tabular}




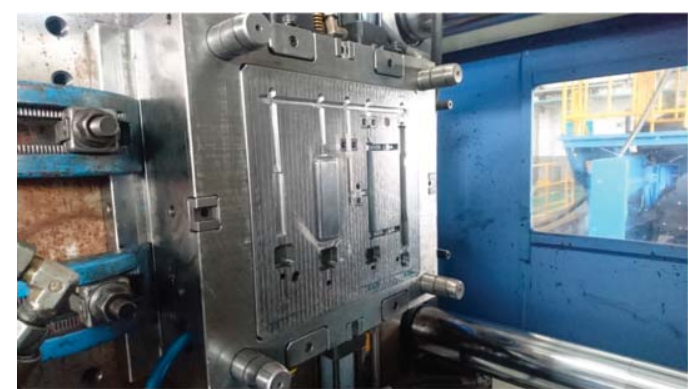

a)

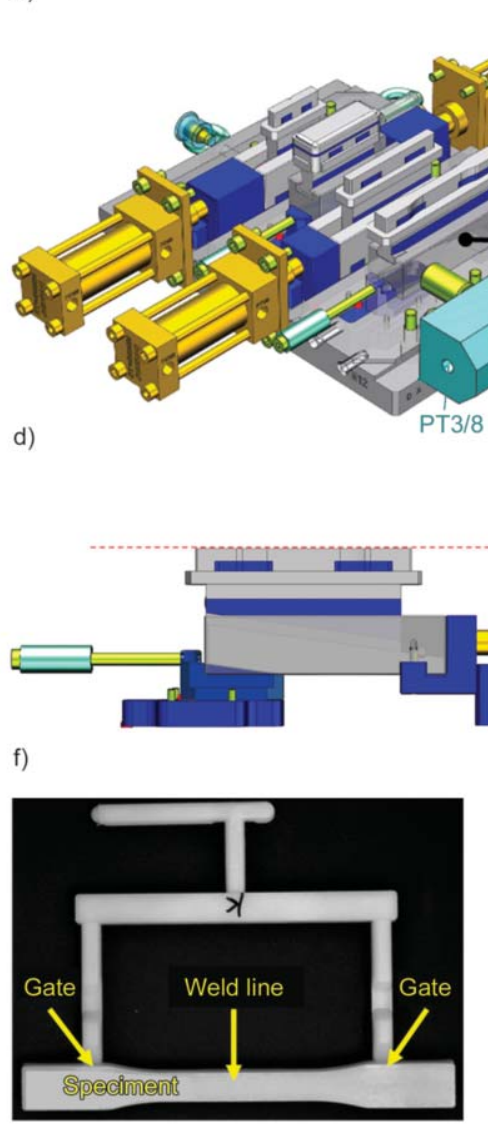

h)

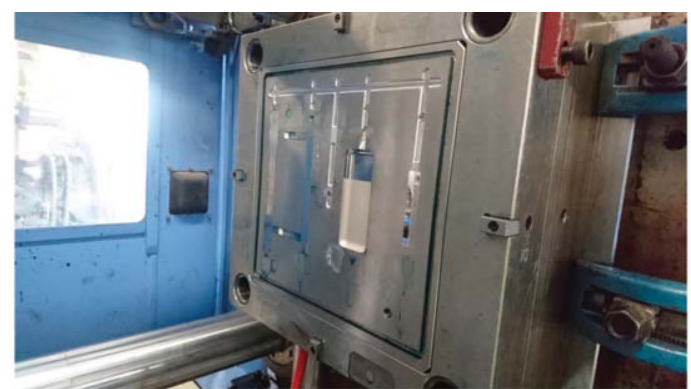

b)

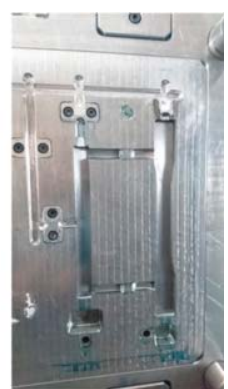

c)

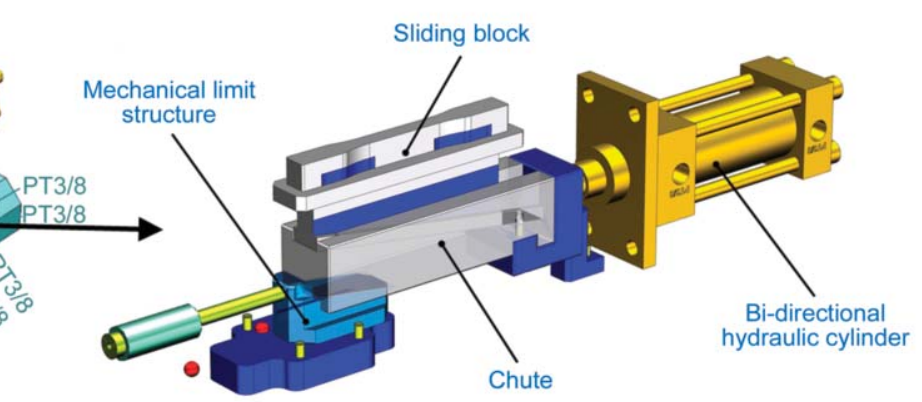

e)

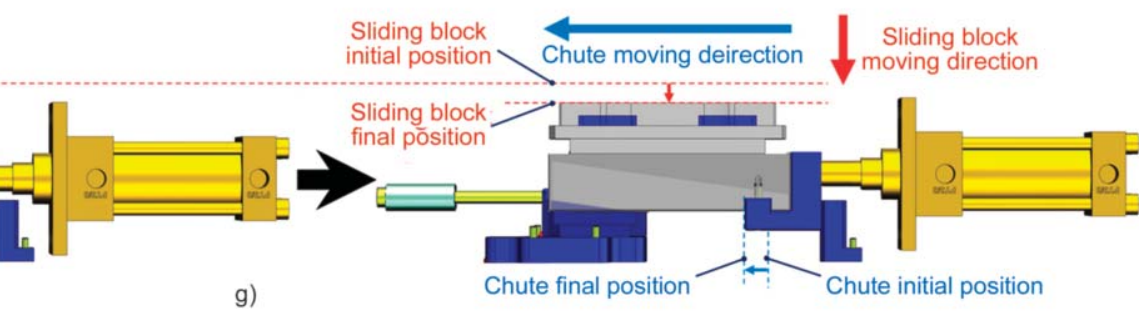

g)

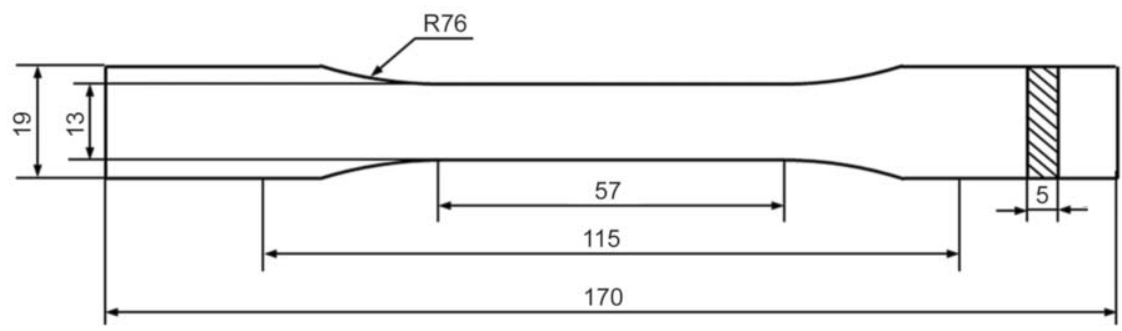

i)

Figure 1. Mold and specimen. a) Mold core plate, b) mold cavity plate, c) mold core plate detail, d) cavity depth control structure, e) mechanical coordination structure, f) initial state of mechanical coordination structure, g) final state of mechanical coordination structure, h) specimen with a bar i) specimen size.

of the bevel coordination between the chute and the sliding block, the sliding block moves along the direction of the red arrow shown in Figure if to increase the depth of the mold cavity, and finally reaches the state as shown in Figure 1g. The mechanical limiting structure is used to limit the final position of the movement of the chute. Thus the final position of the sliding block is controlled accurately [22]. The foamed specimens were obtained, as shown in Figure 1h, and the specimen size is shown in Figure 1i.

\subsection{Characterizations and testing methods \\ 2.2.1. Observation of fracture, surface and internal morphology of weld lines}

The fracture area of the specimens with weld lines after tension test was cut directly to observe the fracture morphology of the weld lines. The untreated specimens with weld lines were cut according to Figure $2 \mathrm{a}$ for observation of the surface morphology of the weld lines. As shown in Figure 2a, the specimens were first cut, then the cut specimens were immersed in liquid nitrogen for 15 minutes. After extraction, 


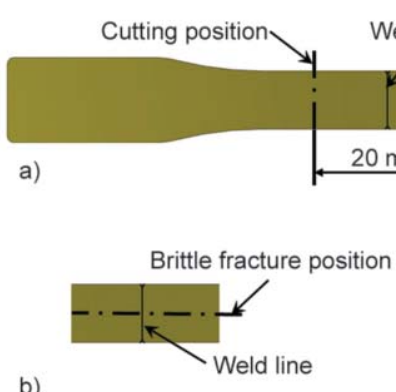

b)

Figure 2. The sampling positions. a) Cutting positions of weld line area, b) brittle fracture. position of weld line area, c) brittle fracture position of area without weld line.

the weld line area of the specimens were taken for brittle fracture sampling according to the position shown in Figure $2 b$ to observe the internal morphology of the weld lines. The parts outside the weld line area of the specimens were brittle fracture treated according to the position shown in Figure 2c for observing the morphology of the inner cell of the specimens, among them, where position I and II shown in Figure 2c represent observation positions, respectively. In addition, by adjusting the holding time, the specimens retaining the reticular structure can be obtained. The brittle fracture of the reticular structure is sampled for its morphology observation.

A Japanese electronics JSM-780F scanning electron microscopy was used to observe fracture section, surface and internal morphology of weld lines, the test voltage range is $5 \mathrm{KV}$, and the magnification range is 60-200 times. The observation surfaces of all specimens were sprayed with gold because polymer materials are insulating materials.

The average cell density was calculated by using the Equation (1) proposed by Kumar and Suh [31]:

$N_{\mathrm{j}}=\left(\frac{n_{\mathrm{j}} M^{2}}{A}\right)^{\frac{3}{2}}$

where $N_{\mathrm{j}}$ is the average cell density, [cells $\left./ \mathrm{cm}^{3}\right] ; n_{\mathrm{j}}$ is the number of cells observed in SEM photo; $M$ is the magnification factor of the SEM photo; $A$ is the SEM photo area of the selected observation area, $\left[\mathrm{cm}^{2}\right]$. Three specimens were taken at the same location, and the average diameter of cells and cells density observed by SEM were taken as the mean diameter and average density of cells.

\subsubsection{Mechanical properties and weight reduction}

A universal electronic test machine (SANS CMT5105) with an extensometer was used to test the tensile strength of the tensile specimens, the tensile rate is $2 \mathrm{~mm} / \mathrm{min}$. At least five specimens were tested in each test condition to avoid accidental errors, and the average values were used as the results. In addition, the final values of mechanical properties were divided by the density of the specimens to obtain the specific strength, which is used for comparison and improving the intuition and accuracy of comparison. The total weight reduction of the specimens were calculated by density method, where a high precision solid density tester (DX-120X) was used to measure the density of core-back chemical foam injection molding specimens and conventional chemical foam Equation (2) [22], the weight reduction of the corresponding specimens was calculated:

$\delta_{\mathrm{i}}=\left(1-\frac{\rho_{\mathrm{i}}}{\rho_{0}}\right) \cdot 100 \%$

where $\rho_{0}$ is the density of the conventional injection molding specimens, when $i=1, \delta_{1}$ and $\rho_{1}$ represent the weight reduction and density of core-back CFIM specimens, respectively, when $i=2, \delta_{2}$ and $\rho_{2}$ represent the weight reduction and density of CFIM specimens, respectively.

\section{Results and discussion \\ 3.1. Special reticular structure in weld line area}

Based on the above experimental methods and the technological parameters of foam injection molding in Table 1, the core-back chemical foam injection molding experiments were carried out. By adjusting the holding pressure and holding pressure time, a kind of short shot specimen with necking structure was obtained, and the special weld line had not formed yet at this time, as shown in Figure $3 \mathrm{a}$.

Figure 3 shows the photos and SEM micrographs of the surface and fracture section of the specimen with necking structure. In the figure, the yellow arrow direction indicates the core-back direction, and the white arrow direction indicates the main direction of the tensile action on the specimen. Figure 3a shows a photo of a specimen with necking structure. It can 
be seen that there is obvious necking phenomenon in the area where weld line exists. The surface of the necking area is not smooth and full of pits. Figure $3 \mathrm{~b}$ and $3 \mathrm{e}$ are photo and SEM photo of the necking area parallel to the core-back direction, respectively. Figure $3 \mathrm{c}$ and $3 \mathrm{f}$ are photo and SEM photo of the necking area perpendicular to the core-back direction, respectively. It can be seen from the figures that there are not only pits on the surface of the necking area, but also wiredrawing of polymers, and these pits and wired polymers align in the same direction. Figure $3 \mathrm{~d}$ and $3 \mathrm{~g}$ are cross-section and SEM micrographs of the necking area, respectively. It can be seen from the figures that there are holes and polymer wiredrawing phenomena in the necking area as well as on the surface. In the necking region, the orientated voids and wiredrawn polymer melts form a special three-dimensional reticular structure.

The formation reason of this special reticular structure is due to that core-back is carried out immediately once the formation stage of common weld lines is completed. At this time, the polymer melt is not completely cooled and solidified. With the mold core retreating, the internal pressure of the polymer melt decreases, and the formed cells grow up gradually and form a series of larger cells. As the mold core continues to retreat, the cells in the core grow rapidly and merge to form a large cavity, while the polymer melt adheres to the inner surface of the cavity under the adsorption of the cavity, forming a layer of skin. Finally, the skin formed by the polymer and the cavity formed by the internal cells composite a shell structure with a complete appearance and a cavity inside [22]. During the formation of the shell, due to the rapid expansion of volume, the polymer melt is subjected to a tensile action perpendicular to the coreback direction. Due to the relatively weak connection at the weld line, the shell skin is pulled apart along the white arrow direction shown in Figure 3a under the influence of this tension. At the same time, because the uncooled polymer melt is still in the viscous flow state, the skin of the shell structure will not be directly pulled off at the weld line, but the polymer melt which is still in the viscous flow state will be stretched into filaments along the direction of tension and orientation, forming a special reticular structure, and with the occurrence of severe strain and necking, the structure shown in Figure 3 is finally

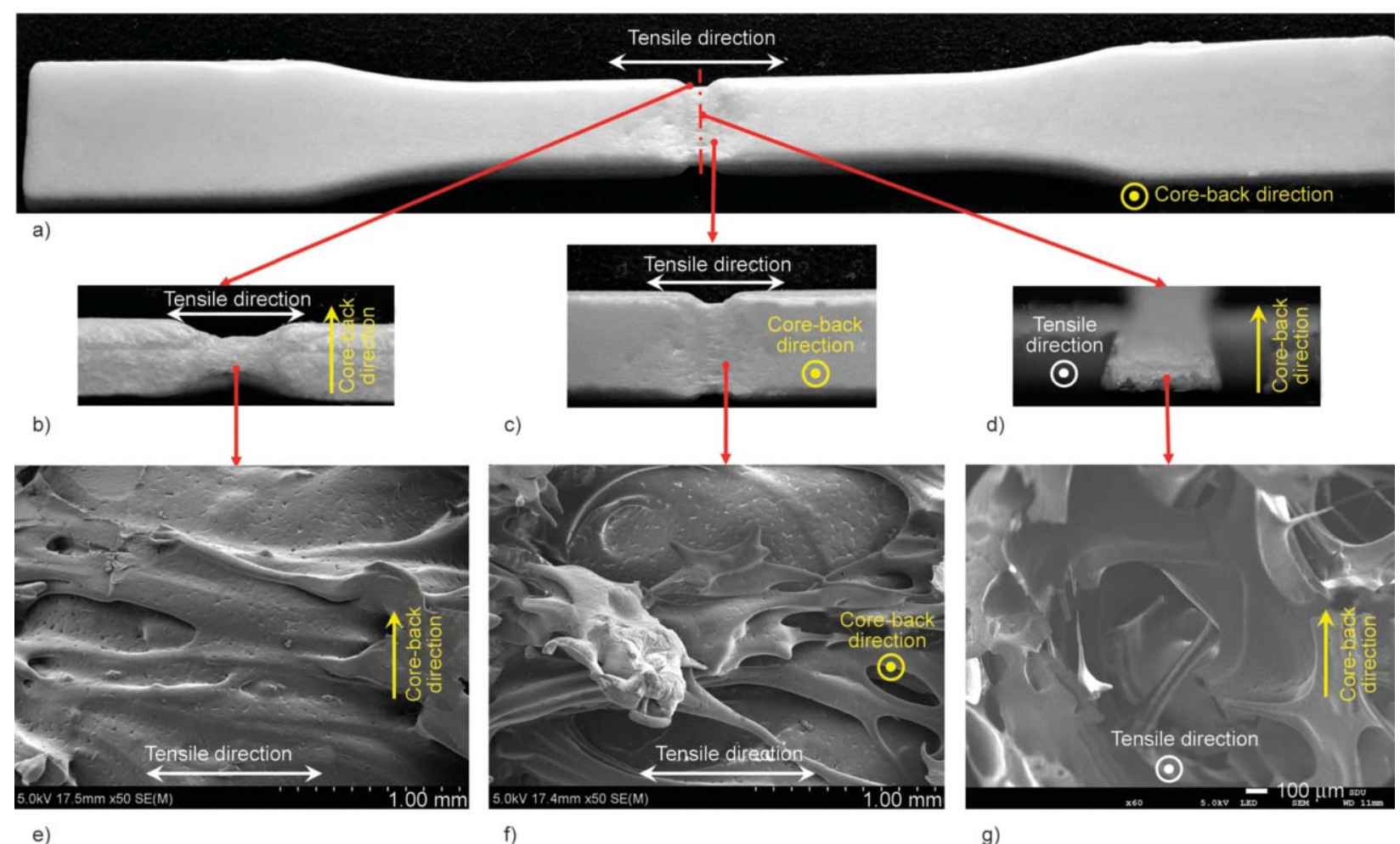

e)

f)

g)

Figure 3. Photos and SEM micrographs of the outer surface and fracture of necking structure of specimen. a) Specimen with necking, b) photo of the necking area parallel to the core-back direction, c) photo of the necking area perpendicular to the core-back direction, d) cross-fractureal photo of necking area, e) SEM of the necking area parallel to the core-back direction, f) SEM of the necking area perpendicular to the core-back direction, g) cross-fractureal SEM of necking area. 
formed. In addition, due to the necking of the shell in this area, the skin of the shell in this area can't be tightly close to the inner surface of the mold cavity, thus forming an unfilled area between the skin of shell and the mold cavity. This area will eventually be filled with newly injected polymer melt under the effect of holding pressure after core-back movement, thus forming a special weld line structure.

\subsection{Morphology of weld line area}

\subsubsection{Surface and internal morphology of weld line area}

Figure 4 shows the surface morphology and inner cell morphology of the specimens with special weld lines obtained by core-back chemical foam injection molding method and the specimens with common weld lines obtained by conventional chemical foam injection molding method. Figure $4 \mathrm{a}$ and $4 \mathrm{~b}$ show SEM micrographs of the weld line area of the specimens with special weld lines, a weld line can be observed on the surface of the specimens. However, as shown in Figure 4e and 4f, besides a visible weld line, there are a series of complex lines around the weld line. This is because in the conventional foam injection molding process, the polymer melt directly contacts the inner surface of the mold cavity with relatively low temperature when filling the cavity, which makes the polymer melt in a relatively low temperature external environment during the whole process, and this low temperature external environment will

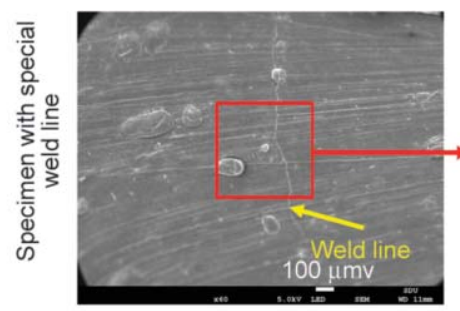

a)

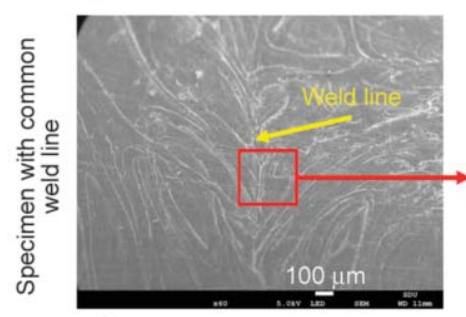

e)

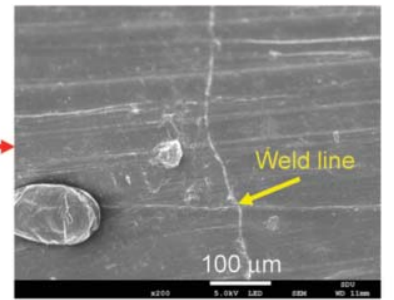

b)

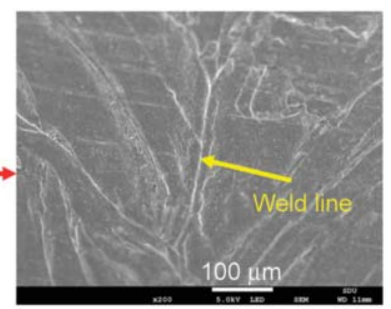

f) make the cooling and solidification speed of the polymer melt faster. When the two polymer melt flow fronts meet each other, the cells moving between the polymer melt and the mold cavity are deformed and cracked due to the fountain effect, and the cracked cells are cooled and solidified before they are completely flattened. Finally, while the weld lines are formed, a series of more complex phenomena are formed on the surface of the weld lines, as shown in Figure $4 \mathrm{e}$ and $4 \mathrm{f}$. The pattern is the same as the formation of fish scale and gas mark defects on the surface of foam injection molding parts [32-35].

However, for the core-back chemical foam injection molding, there is a layer of skin formed by the cooling of polymer melt between polymer melt and the inner surface of mold cavity. This skin plays a certain role of thermal insulation and heat preservation in the process of filling polymer melt, which makes the polymer melt flow fronts keep a higher temperature when they meet each other. When the melt fills the mold cavity in the reticular structure area, the cells between the polymer melt and the mold cavity are flattened by the melt pressure after the cells break down due to the fountain effect. Therefore, the surface near the weld line of the specimen is relatively smooth, and there is no series of complex lines like those in Figure 4e and 4f.

Figure $4 c$ and $4 d$ are SEM micrographs of specimens with special weld lines. A large number of deformed cells can be observed from the photos, but no obvious

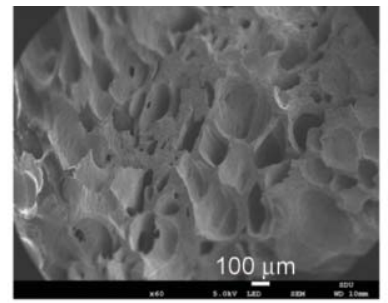

c)

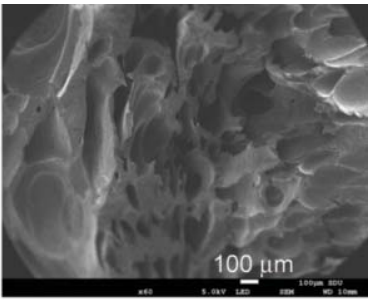

d)
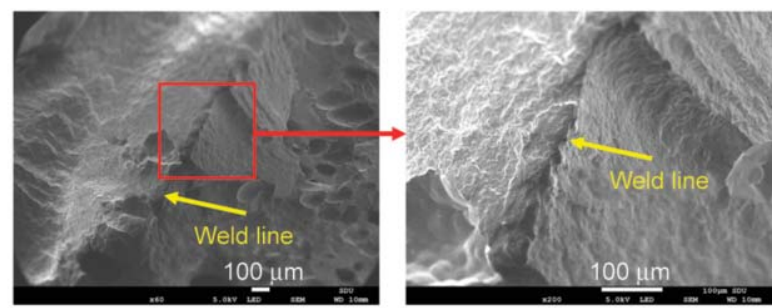

h)

Figure 4. SEM micrographs of the surface and interior of the weld line area. a), b) SEM micrographs of surface morphology of weld line area of specimens with special weld lines, c), d) SEM micrographs of the internal morphology of the welding line area of specimens with special welding lines, e), f) SEM micrographs of surface morphology of weld line area of specimens with common weld lines, g), h) SEM micrographs of the internal morphology of the welding line area of specimens with common welding lines. 
weld line. However, as shown in Figure 4g and 4h, in the weld line area of the specimen with common weld line, there are fewer cells, and obvious weld line can be observed. This is because when using core-back chemical foam injection molding method, newly injected polymer melt is injected into the shell through the gate, but the melt does not directly contact the inner surface of the mold cavity due to the existence of unique shell structure. Under the thermal insulation effect of shell skin, the polymer melt temperature is relatively high, the viscosity of polymer melt is relatively low, and the space is sufficient. After cell nucleation, the resistance to growth of cells is relatively low, so there are more cells in the special weld line area. In addition, when the polymer melt arrives at the reticulate structure and fills this region, the melt flow front is cut by the reticulate structure, and the flow direction is changed under the induction of reticulate structure cavity, which makes the polymer melts in this region cross-flow and intertwine, so there is no obvious weld line in the weld line area. Moreover, the complex flow of polymer also causes the deformation of cells.

\subsubsection{Fracture morphology}

Figure 5 shows fracture photos and SEM micrographs of specimens with weld lines. Figure $5 \mathrm{~d}$ and $5 \mathrm{e}$ are the fracture photos of specimen with special weld line and with common weld line, respectively. It can be seen from the photos that the fracture surface of the specimen with special weld line is rough and there are cells on the fracture, but the fracture surface of the specimen with common weld line is relatively flat, and no cells are observed. The two kinds of specimens were tightly packed together at the time of loading, so Figure $5 \mathrm{~b}$ can show the fracture edge SEM photo of specimen with special weld line (left) and specimen with common weld line (right). Figure $5 \mathrm{a}$ and $5 \mathrm{c}$ are their locally enlarged SEM micrographs, respectively. It can be seen from

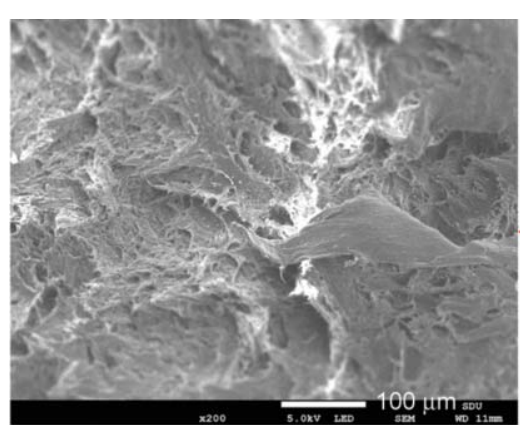

a)

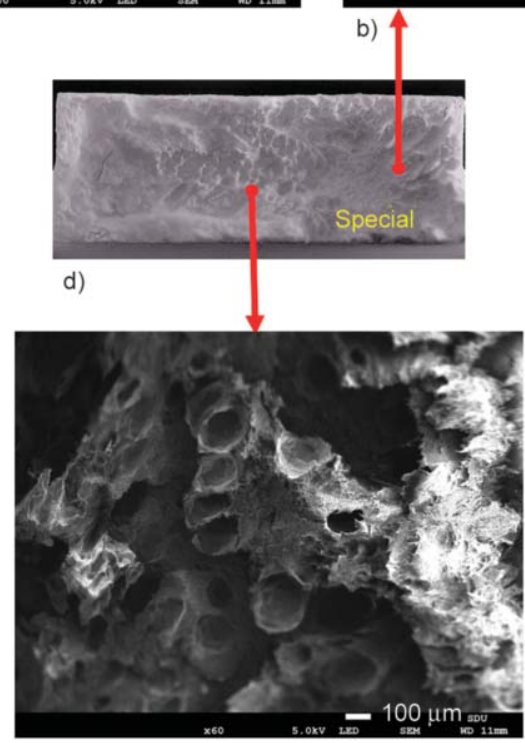

f)

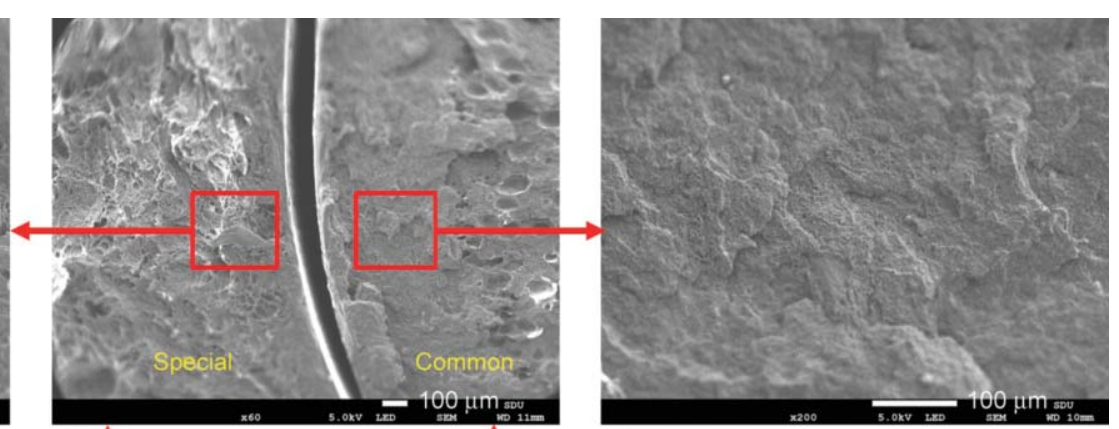

c)

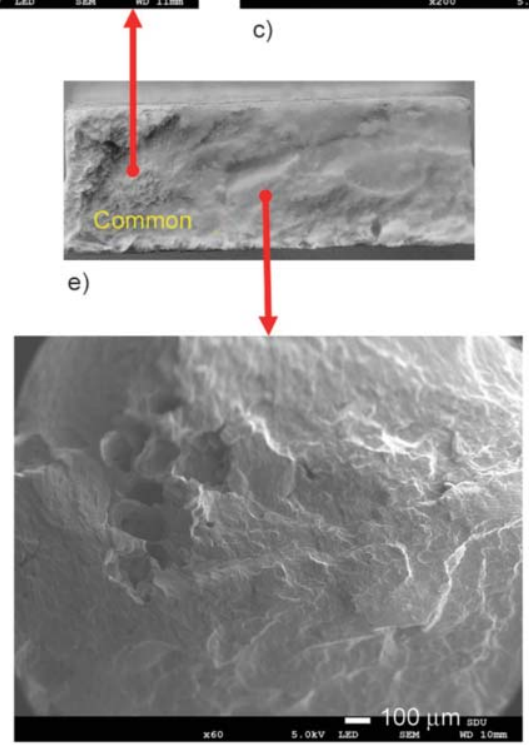

g)

Figure 5. Fracture photos and SEM micrographs of specimens with weld lines. a) Fracture edge SEM photo of specimen with special weld line, b) fracture edge SEM photo of specimen with special weld line (left) and specimen with common weld line (right), c) fracture edge SEM photo of specimen with common weld line, d) fracture edge photo of specimen with special weld line, e) fracture edge photo of specimen with common weld line, f) fracture core SEM photo of specimen with special weld line, g) fracture core SEM photo of specimen with common weld line. 
the figures that the fracture edge of the specimen with special weld line is rough and burr, and generally presents flocculent morphology. However, the fracture edge of the specimen with common weld line is fairly flat, which is closer to the brittle fracture morphology. Figure $5 \mathrm{f}$ and $5 \mathrm{~g}$ are the fracture core SEM micrographs of specimen with special weld line and with common weld line, respectively. From the photos, it can be seen that there are cells and burrs in the fracture core of the specimen with special weld line. Like the edge of the fracture, the surface of fracture core is generally linear and flocculent. However, the fracture core of the specimen with special weld line has few cells and smooth surface, which is more similar to the brittle fracture as same as the edge of the fracture.

The reason for the above phenomena is that when the weld line of the specimen with special weld line is formed, due to the insulation effect of the shell structure, the temperature of the melt flow fronts is high and the bonding of melt flow fronts is relatively good. At the same time, because of the existence of the reticular structure, the polymer melts will crossflow and intertwine during the formation of the weld line. This makes the polymer bonding at the weld line of specimen with special weld line better than that of the specimen with common weld line. When the specimen is stretched, the polymer at the weld line drags each other and burrs are formed, which make the fracture generally appear as a flocculent shape. However, when the weld line of the specimen with common weld line is formed, the melt front temperature of the polymer melt is relatively low. The polymer melt on the surface of the specimen is solidified to a certain extent, and the bonding is relatively weak. In the process of the formation of the common weld line, the flow of the polymer melt is relatively simple, and the phenomenon of cross-flow will not occur. When the polymer is stretched, the polymer at the weld line almost does not drag each other. The fracture is relatively flat and its morphology is closer to that of brittle fracture section.

\subsection{Cell morphology}

Figure 6 shows the cell morphology and cell density of specimen with special weld line and with common weld line at the section of brittle fracture position shown in Figure $2 b$ and $2 c$, respectively. In the figure, position I is far gate end fracture in non-weld area and position II is near gate end fracture in non-weld area. Figure 6a-c are SEM micrographs of brittle fracture cell morphology in position I, position II and weld line area of specimen with special weld line, respectively. It can be seen from the photos that the cell size in the three positions is all relatively large, and the diameters are 100-250 um. The brittle fracture cell morphology of specimen with common weld line in these three regions is shown in Figure 6d-6f, respectively. It can be seen that the cell diameter at position I and position II is smaller than that of the specimen with special weld line, the cell diameters are about 70-150 um. The cell size of specimens with common weld line is relatively small because the conventional foam injection molding can only provide limited space for the growth of cells after nucleation, the cooling speed of polymer melt is fast, the time for cell nucleation and growth is insufficient, a large number of gas spills from polymer melt and is eliminated through the exhaust system of the mold, and the gas involved in cell growth is relatively less. However, the core-back chemical foam injection molding can provide more space for the cell growth after nucleation. At the same time, under the protection of the skin structure of the special shell structure, the polymer melt temperature is high, the cooling and solidification speed is relatively slow, which also provide more time for the nucleation and growth of cells. In addition, under the protection of this shell structure, the gas overflow in polymer melt is less, which ensures and more gas can participate in the growth of cells. The cell size of specimens with special weld line is larger than that of specimens with common weld line.

After calculation, the average cell density of specimens with special weld lines at these three locations is $2.49 \cdot 10^{5}, 1.98 \cdot 10^{5}$ and $1.86 \cdot 10^{5} \mathrm{cell} / \mathrm{cm}^{3}$, respectively. The average cell density of specimens with common weld lines at these three locations are $2.68 \cdot 10^{5}, 1.40 \cdot 10^{5}$ and $6.8 \cdot 10^{5} \mathrm{cell} / \mathrm{cm}^{3}$, respectively. Figure $6 \mathrm{~g}$ is a comparison of cell density between the two kinds of specimens, it can be seen that the average cell density of the specimens with special weld lines does not change much in every part, while the average cell density of the specimens with common weld lines is larger at position I, and the cell density decreases obviously at position II and weld line area. This is because with the increase of distance from the gate in the filling process of conventional foam injection, the gas in the polymer melt overflows from the melt and is discharged through the exhaust 


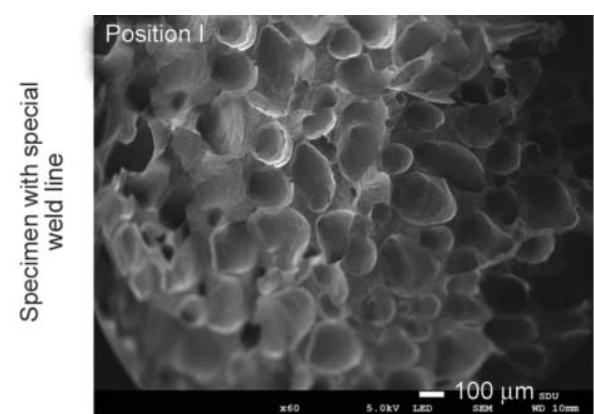

a)

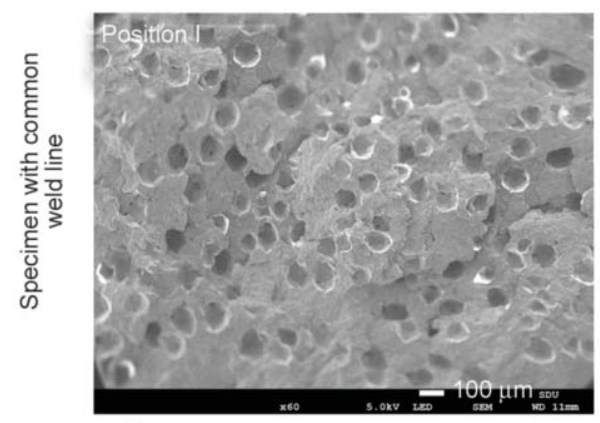

d)

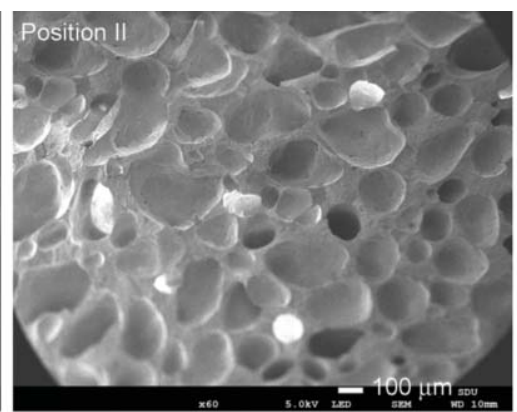

b)

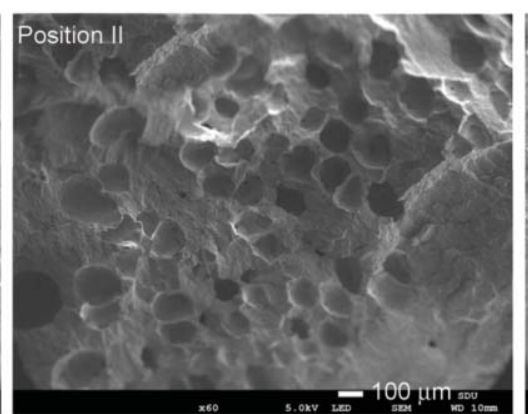

e)

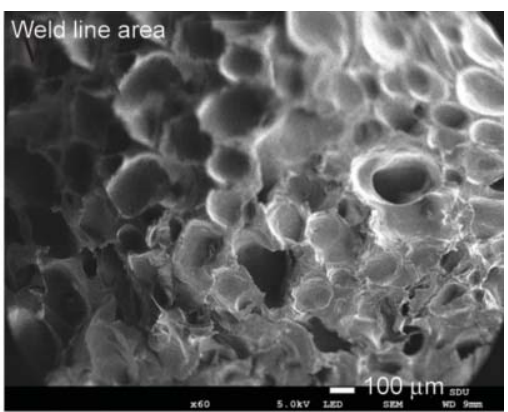

c)

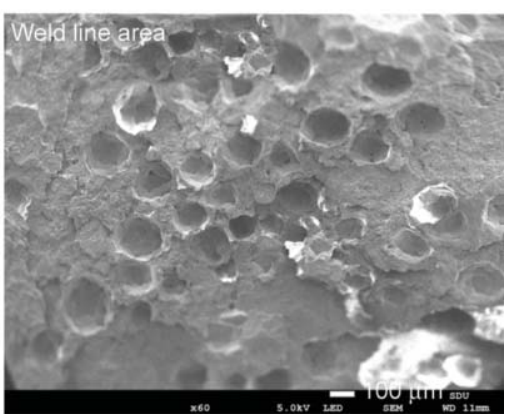

f)

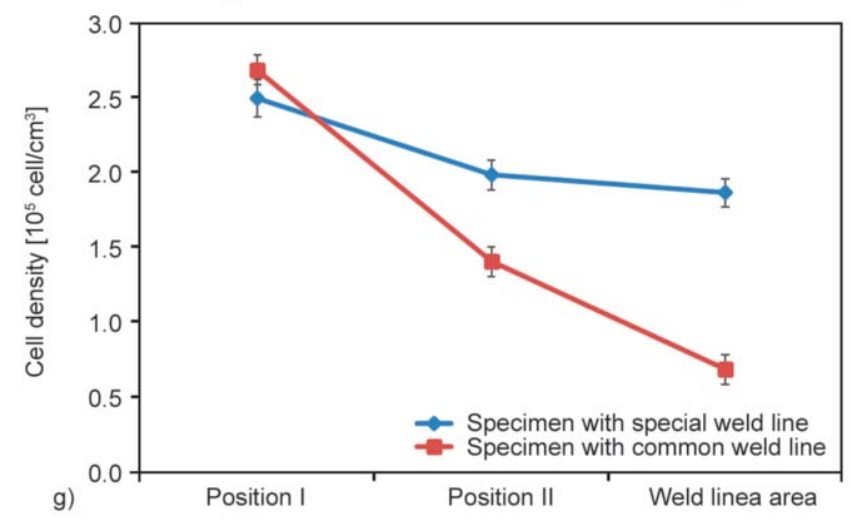

Figure 6. Brittle fracture cell morphology SEM micrographs of inner cells and comparisons of cell density at different positions of specimens. a) Position I of specimen with special weld line, b) position II of specimen with special weld line, c) weld line area of specimen with special weld line, d) position I of specimen with common weld line, e) position II of specimen with common weld line, f) weld line area of specimen with common weld line, g) comparisons of cell density.

structure of the die, resulting in a large reduction of the gas involved in cell growth. Almost all the gas in the polymer melt which is farthest from the gate at the weld line is overflowing, so the cell density in the specimens with common weld line decreases obviously, as shown in Figure $6 \mathrm{~g}$. However, in the process of core-back chemical foam injection molding, because the foaming process is mainly carried out in the special shell structure, the phenomenon of gas overflow from the polymer melt is obviously inhibited under the protection of the shell structure, so the distribution and size of the cells in all positions are relatively uniform.

\subsection{Weight reduction and mechanical properties}

Measured by a high precision solid density tester (DX-120X), the average density of pure PP specimens is $0.90 \mathrm{~g} / \mathrm{cm}^{3}$, and the average density of the foamed specimens with special weld lines is $0.69 \mathrm{~g} / \mathrm{cm}^{3}$. Therefore, the weight reduction is $23.3 \%$. While the the average density of the foamed specimens with common weld lines is $0.81 \mathrm{~g} / \mathrm{cm}^{3}$, and the weight reduction is only $10 \%$. This is because the specimens with special weld lines have more uniform and larger cells than those with common weld lines, as shown in Figure 6. Although there is little difference in cell 
density in some regions, the specimens with special weld lines have larger cell size and thinner cell wall, which makes more space occupied by cells in the specimens, thus increasing the weight reduction.

For a more intuitive comparison, the specific tensile strength of the specimens is obtained by dividing the measured tensile strength by the density of the corresponding specimens. Figure 7 shows the comparison of tensile strength, specific tensile strength, and elongation at break between unfoamed specimens with common weld lines, foamed specimens with special weld lines and foamed specimens with common weld lines. The tensile strength of unfoamed specimens with common weld lines is $18.7 \mathrm{MPa}$, the specific tensile strength is $0.021 \cdot 10^{6} \mathrm{Nm} / \mathrm{kg}$, and the elongation at break is $17 \%$. The tensile strength of foamed specimens with special weld lines is $16.06 \mathrm{MPa}$, the specific tensile strength is $0.023 \cdot 10^{6} \mathrm{Nm} / \mathrm{kg}$, and the elongation at break is $37.7 \%$. The tensile strength of foamed specimens with common weld lines is $12.29 \mathrm{MPa}$, the specific tensile strength is $0.015 \cdot 10^{6} \mathrm{Nm} / \mathrm{kg}$, and the elongation at break is only $5.8 \%$. The tensile strength, specific tensile strength and elongation at break of specimens with special weld lines were increased by $30.7,53.3$ and $550 \%$, respectively, compared with foamed specimens with common weld lines. In addition, compared with unfoamed specimens with common weld lines, although the tensile strength of specimens with special weld lines was decreased by $14 \%$, the specific tensile strength and elongation at break were increased by 9.5 and $122 \%$, respectively.

In conclusion, the specimens with special weld lines have obvious mechanical properties superiority to those with common weld lines. The main reasons are as follows:

Firstly, under the thermal insulation of the shell structure of core-back chemical foam injection molding, the newly injected polymer melt can maintain high temperature. When the weld lines are formed, the polymer flow fronts which encounter each other can be more closely bonded.

Secondly, the specimens with special weld lines have a special reticular structure in the weld line area. This reticular structure is formed in the core-back stage. During its formation process, the polymer melt is oriented by the tensile action perpendicular to the core-back direction, and coated by newly injected polymer melt during the formation of the special weld lines. In the process of newly injected polymer melt encapsulating reticular structure, the melt generates cross flow and intertwining due to the influence of reticular structure, finally resulting in closer bonding.

Thirdly, the reticular structure of the specimens with special weld lines has certain orientation, and after being coated by polymer melt, it acts as a fibre reinforcement in the weld line area.

Figure 8 shows the fracture process of specimen with special weld line and specimen with common weld

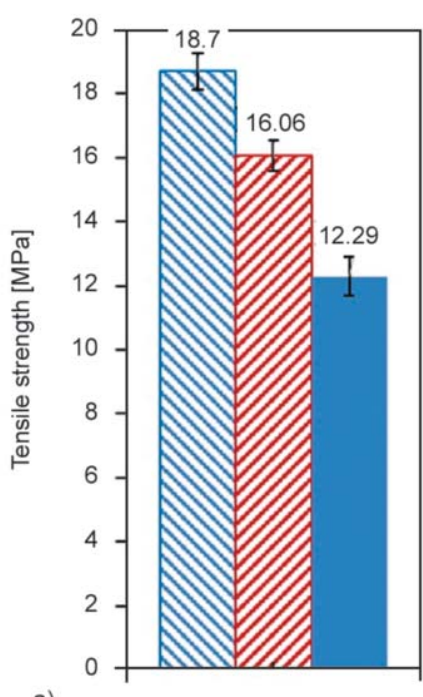

a)

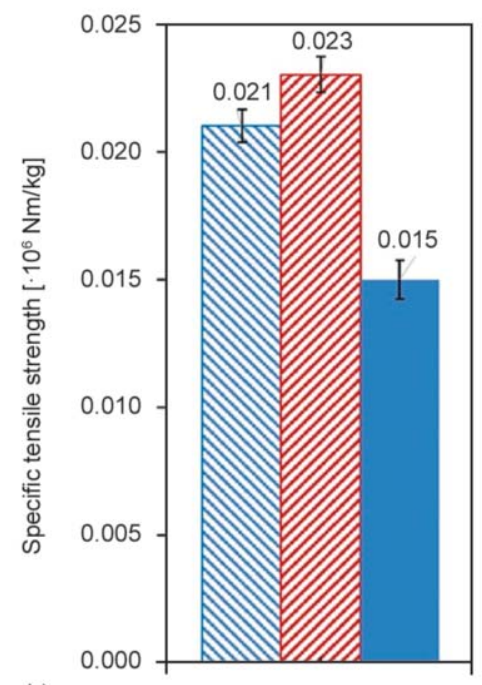

b)

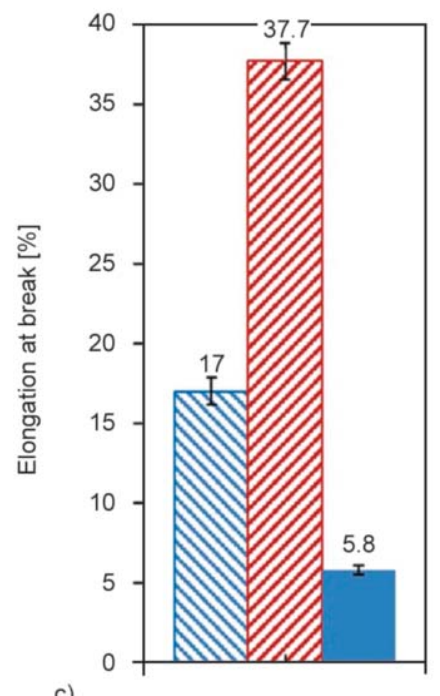

c)

$\checkmark$ Unfoamed specimen wirh common weld line Foamed specimen wirh special weld line Foamed specimen wirh common weld line

Figure 7. Comparison of mechanical properties. a) Tensile strength, b) specific tensile strength, c) elongation at break. 
line, where the tensile rate is $2 \mathrm{~mm} / \mathrm{min}$. Figure $8 \mathrm{a}$, $8 \mathrm{e}$ and $8 \mathrm{i}$ are the initial states of foamed specimen with special weld line, foamed specimen with common weld line and unfoamed specimen with common weld line. Figure $8 \mathrm{~b}, 8 \mathrm{f}$ and $8 \mathrm{j}$ are the photos of the three kinds of specimens when the weld lines begin to whiten. Figure $8 \mathrm{c}, 8 \mathrm{~g}$ and $8 \mathrm{k}$ are the photos of the three kinds of specimens when the weld lines begin to crack. Figure $8 \mathrm{~d}, 8 \mathrm{~h}$ and 81 are the photos of the three kinds of specimens when the weld lines are completely broken. By comparison, it can be found that the time taken for the specimen with special weld line to reach the same state with common weld line is consistent with the difference of elongation at break between the three kinds of specimens.

Comparing Figure $8 \mathrm{~b}$ with $8 \mathrm{f}$ and $8 \mathrm{i}$, it can be found that the specimen with special weld line whiten both at the weld line and the areas outside the weld line, while the specimen with common weld line only whiten at the weld line. This is because the mechanical

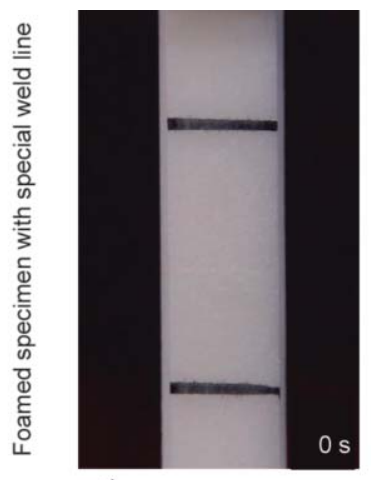

a)

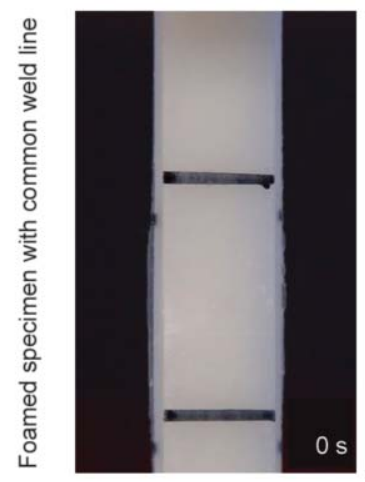

e)

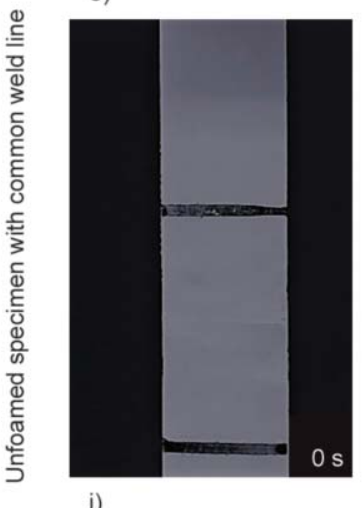

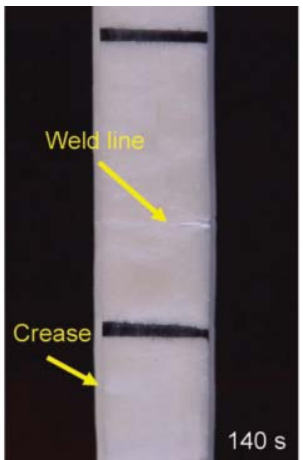

b)

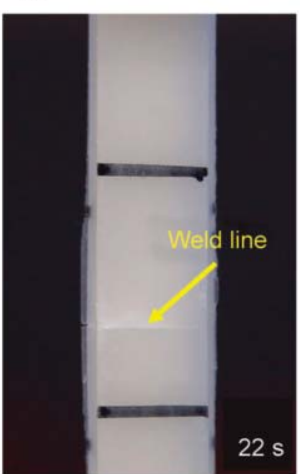

f)

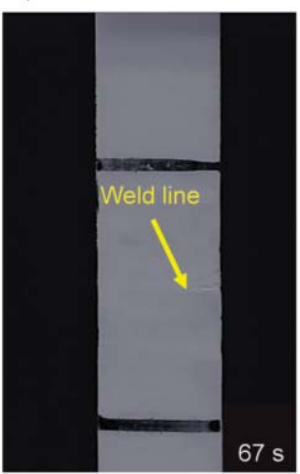

j)

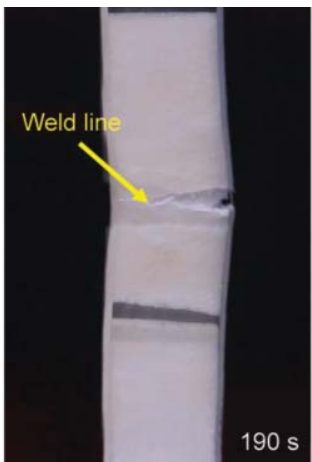

c)

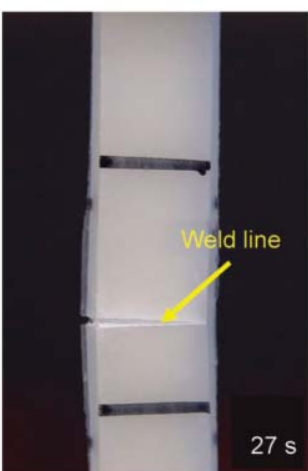

g)

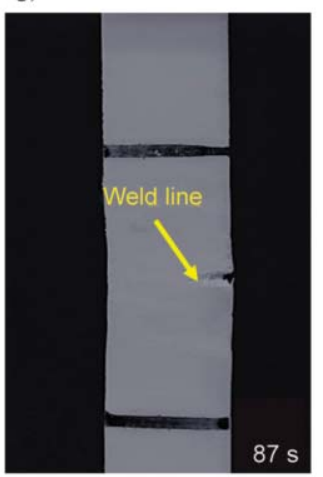

k)

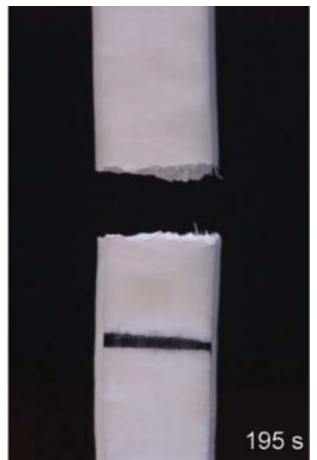

d)

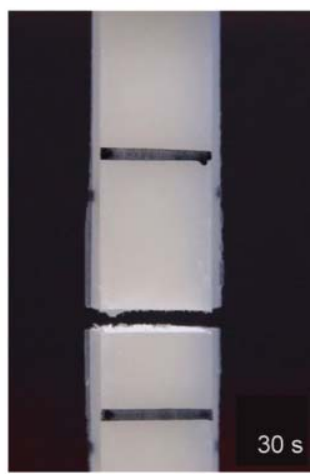

h)

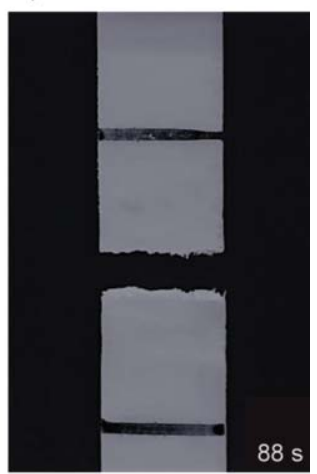

I)

Figure 8. Tensile fracture process of specimens. a) Initial state of foamed specimen with special weld line, b) the foamed specimen with special weld line begin to whiten, c) the foamed specimen with special weld line begin to crack, d) complete disconnection of foamed specimen with special weld line, e) initial state of foamed specimen with common weld line, f) the foamed specimen with common weld line begin to whiten, g) the foamed specimen with common weld line begin to crack, h) complete disconnection of foamed specimen with common weld line, i) initial state of unfoamed specimen with common weld line, $\mathrm{j}$ ) the unfoamed specimen with common weld line begin to whiten, k) the unfoamed specimen with common weld line begin to crack, 1) complete disconnection of unfoamed specimen with common weld line. 
properties in weld line of the specimens with special weld lines are similar to those of the areas outside the weld line. In the process of tension, the weld lines are not easy to be pulled apart and deformed, which makes the whole observation area have a relatively uniform deformation. However, the mechanical properties in weld line of the specimens with common weld lines are much lower than those of the areas outside the weld line. During the tensile process, the weld lines are first pulled out and deformed, which makes only the weld lines in the observation area undergo obvious deformation. Comparing Figure 8c, $8 \mathrm{~g}$ and $8 \mathrm{k}$, it can be found that during the fracture process of the specimen with special weld line, polymer is pulled out from the core of the specimen, which makes the fracture section of the specimens uneven. However, in the fracture process of the specimen with common weld line, almost no polymer is pulled out from the core of the specimen, and the fracture section is relatively flat.

\section{Formation principle of special weld line}

Through the above experimental analysis, the weld lines of the specimens obtained by core-back chemical foam injection molding are obviously different from those of the specimens obtained by conventional foam injection molding wether in formation process or internal structure. In the conventional foam injection process, the weld line is formed by the combination of two or more polymer melt flow fronts when polymer melt fills the mold cavity. The flow direction of melt fronts is single when they meets, and the internal structure of the weld line is also simple. However, in the core-back chemical foam injection process, a special reticular structure was formed before the formation of special weld lines. During the formation of special weld lines, the special reticular structure were coated by newly injected polymer melts, which induces the polymer melts cross-flowing and intertwining and makes the internal structure of the weld lines complex.

Through the above research and analysis, this paper gives the formation process and principle of this special weld line, as shown in Figure 9. The process can be divided into three stages: formation stage of the common weld line, formation stage of the special reticular structure, and formation stage of the special weld line.

Stage I: formation stage of common weld line. In this stage, the core of the mold is always at the front end. The melt filling process in this stage is the same as that of the conventional foam injection molding, as shown in Figure 9a, where the direction of the red arrow is the direction of the melt flow. In the whole filling process, the position of the core remains unchanged until the two melt flow fronts meet each other and form a weld line. The weld line formed in this stage is the same as that obtained by conventional foam injection molding, as shown in Figure 9b.

Stage II: formation stage of special reticular structure. Once the stage I is finished, the core-back is started immediately, as shown in Figure 1c. The direction of the black arrow in Figure 9c is the coreback direction. When the mold core is withdrawn to

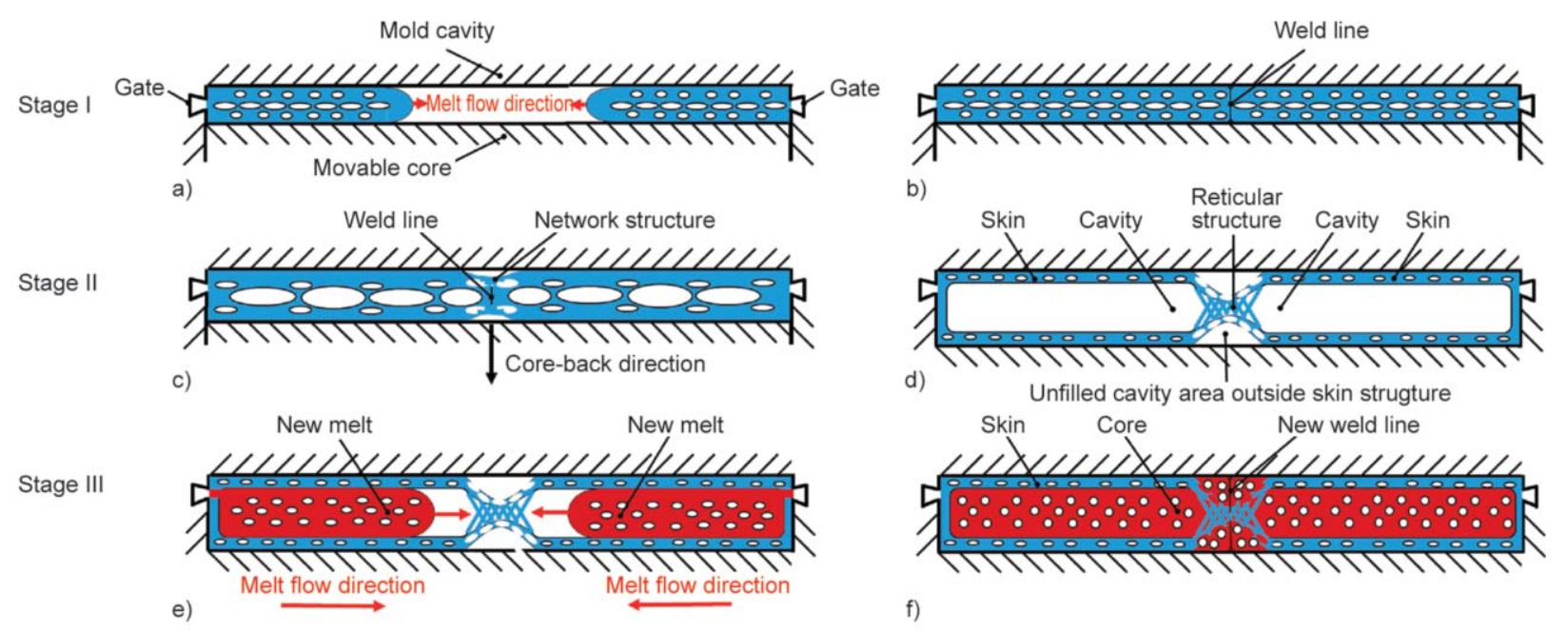

Figure 9. Schematic diagram of special weld line formation process and principle. Stage I: formation stage of common weld line, Stage II: formation stage of special reticular structure, Stage III: formation stage of special weld line. a) Conventional injection, b) end of conventional injection, c) core-back, d) end of core-back, e) secondary filling, f) end of secondary filling. 
the set depth, core-back stops. Based on previous studies [22], after core-back, a closed shell structure wrapped by a 'skin' is formed. During the formation of the shell structure, the polymer constituting the skin is subjected to a tension perpendicular to the core-back direction, and at this point, the cortical polymer at the weld line will be gradually pulled apart due to the weak connection. In addition, because part of the polymer melt is still in the viscous flow state in the process of being pulled apart, the skin will not break off at the weld line, but will be drawn, and eventually form a reticular structure. At the same time, due to the necking phenomenon, an unfilled cavity area is formed between the skin and the inner surface of the mold cavity, as shown in Figure 9d.

Stage III: formation stage of special weld line. The holding pressure process is started immediately once the core-back is completed. In this stage, newly injected polymer melt is filled through the gate into the cavity of the 'skin' structure formed in Stage II, as shown in Figure 9e, where the direction of the red arrow is the direction of the melt flow. When two newly injected polymer melts come into contact with the reticular structure and form a weld line, a part of the polymer melt will spill out of the shell skin through the reticular and fill the unfilled mold cavity area. Finally, the newly injected polymer melt completely coats the reticular structure and forms a new weld line, as shown in Figure 9f.

\section{Conclusions}

In this paper, a kind of PP plastic parts with special weld lines were obtained by using core-back foam injection molding with chemical blowing agent. A formation process of this special weld lines was proposed, and its unique formation principle was revealed by comparing with the experimental results of conventional chemical foam injection molding. The surface and internal morphology, fracture morphology, cell structure and mechanical properties of the weld line area of the specimens obtained by coreback foam injection molding and conventional foam injection molding were compared and analyzed. The mechanism of core-back chemical foam injection method in improving the weight reduction effect of the specimens and the mechanical properties of the weld line was clarified. The following main conclusions are drawn.

(1) The weld lines obtained by core-back foam injection molding method have special structure and formation process. In the process of coreback, a special shell structure is formed. At the weld line area, the skin of the shell structure is stretched and a reticular structure is formed. In the following process of new weld lines formation, the newly injected polymer melts crossflow and intertwine when passing through this special reticular structure, which makes the polymer bonding better at the weld lines and enhances the mechanical properties of the weld lines.

(2) The special reticular structure of the plastic parts with special weld lines obtained by core-back foam injection molding method is stretched and oriented in its formation process, and then coated by the newly injected polymer melt to form a special weld line area. This special reticular structure plays a role similar to fiber strengthening in the weld line area and further enhances the mechanical properties of the weld line area.

(3) Compared with the specimens with common weld lines obtained by conventional foam injection molding, the specimens with special weld lines obtained by core-back foam injection molding are protected by the special shell structure, the phenomenon of gas spillover from polymer melt is significantly inhibited, and more gas can participate in the growth of cells, the distribution and size of cells is relatively uniform, which obviously improves the mechanical properties and weight reduction effect of foamed plastic parts.

(4) The specimens with special weld lines obtained in this paper have good tensile strength, specific tensile strength, and elongation at break. They are increased by $30.7,53.3$ and $550 \%$ than those of specimens with common weld lines, respectively. The main reason is that the specimens with special weld lines not only have a relatively uniform internal cell structure in size and distribution, but also have a weld line area with a special reticular structure. The special structure of the weld lines plays an important role in improving the mechanical properties of the weld lines.

\section{Acknowledgements}

The authors are grateful to the National Natural Science Foundation of China (NSFC, Grant No. 51875318) and the Young Scholars Program of Shandong University (Grant No. 2017WLJH23). 


\section{References}

[1] Wang G., Wang C., Zhao J., Wang G., Park C. B., Zhao G.: Modelling of thermal transport through a nanocellular polymer foam: Toward the generation of a new superinsulating material. Nanoscale, 9, 5996-6009 (2017). https://doi.org/10.1039/C7NR00327G

[2] Lee J. W. S., Jing W., Yoon J. D., Park C. B.: Strategies to achieve a uniform cell structure with a high void fraction in advanced structural foam molding. Industrial and Engineering Chemistry Research, 47, 9457-9464 (2008). https://doi.org/10.1021/ie0707016

[3] Shaayegan V., Ameli A., Wang S., Park C. B.: Experimental observation and modeling of fiber rotation and translation during foam injection molding of polymer composites. Composites Part A: Applied Science and Manufacturing, 88, 67-74 (2016).

https://doi.org/10.1016/j.compositesa.2016.05.013

[4] Wong S., Lee J. W. S., Naguib H. E., Park C. B.: Effect of processing parameters on the mechanical properties of injection molded thermoplastic polyolefin (TPO) cellular foams. Macromolecular Materials and Engineering, 293, 605-613 (2008).

https://doi.org/10.1002/mame.200700362

[5] Jahani D., Ameli A., Jung P. U., Barzegari M. R., Park C. B., Naguib H.: Open-cell cavity-integrated injectionmolded acoustic polypropylene foams. Materials and Design, 53, 20-28 (2014).

https://doi.org/10.1016/j.matdes.2013.06.063

[6] Stumpf M., Spörrer A., Schmidt H. W., Altstädt V.: Influence of supramolecular additives on foam morphology of injection-molded i-PP. Journal of Cellular Plastics, 47, 519-534 (2011).

https://doi.org/10.1177/0021955X11408769

[7] Ruiz J. A. R., Vincent M., Agassant J-F.: Numerical modeling of bubble growth in microcellular polypropylene produced in a core-back injection process using chemical blowing agents. International Polymer Processing, 31, 26-36 (2016).

https://doi.org/10.3139/217.3129

[8] Miyamoto R., Yasuhara S., Shikuma H., Ohshima M.: Preparation of micro/nanocellular polypropylene foam with crystal nucleating agents. Polymer Engineering and Science, 54, 2075-2085 (2014).

https://doi.org/10.1002/pen.23758

[9] Wang L., Ando M., Kubota M., Ishihara S., Hikima Y., Ohshima M., Sekiguchi T., Sato A., Yano H.: Effects of hydrophobic-modified cellulose nanofibers (CNFs) on cell morphology and mechanical properties of high void fraction polypropylene nanocomposite foams. Composites Part A: Applied Science and Manufacturing, 98, 166-173 (2017).

https://doi.org/10.1016/j.compositesa.2017.03.028

[10] Ishikawa T., Taki K., Ohshima M.: Visual observation and numerical studies of $\mathrm{N}_{2}$ vs. $\mathrm{CO}_{2}$ foaming behavior in core back foam injection molding. Polymer Engineering and Science, 52, 875-883 (2012).

https://doi.org/10.1002/pen.22154
[11] Spörrer A. N. J., Altstädt V.: Controlling morphology of injection molded structural foams by mold design and processing parameters. Journal of Cellular Plastics, 43, 313-330 (2007). https://doi.org/10.1177/0021955X07079043

[12] Chu R. K. M., Mark L. H., Jahani D., Park C. B.: Estimation of the foaming temperature of mold-opening foam injection molding process. Journal of Cellular Plastics, 52, 619-641 (2016)

https://doi.org/10.1177/0021955X15592069

[13] Heim H-P., Tromm M.: General aspects of foam injection molding using local precision mold opening technology. Polymer, 56, 111-118 (2015).

https://doi.org/10.1016/j.polymer.2014.10.070

[14] Lee J. W. S., Lee R. E., Wang J., Jung P. U., Park C. B.: Study of the foaming mechanisms associated with gas counter pressure and mold opening using the pressure profiles. Chemical Engineering Science, 92, 314-325 (2017).

https://doi.org/10.1016/j.ces.2017.04.005

[15] Ameli A., Jahani D., Nofar M., Jung P. U., Park C. B.: Development of high void fraction polylactide composite foams using injection molding: Mechanical and thermal insulation properties. Composites Science and Technology, 90, 88-95 (2014).

https://doi.org/10.1016/j.compscitech.2013.10.019

[16] Ameli A., Nofar M., Jahani D., Rizvi G., Park C. B.: Development of high void fraction polylactide composite foams using injection molding: Crystallization and foaming behaviors. Chemical Engineering Journal, 262, 78-87 (2015).

https://doi.org/10.1016/j.cej.2014.09.087

[17] Ishikawa T., Ohshima M.: Visual observation and numerical studies of polymer foaming behavior of polypropylene/carbon dioxide system in a core-back injection molding process. Polymer Engineering and Science, 51, 1617-1625 (2011).

https://doi.org/10.1002/pen.21945

[18] Wang L., Ishihara S., Hikima Y., Ohshima M., Sekiguchi T., Sato A., Yano H.: Unprecedented development of ultrahigh expansion injection-molded polypropylene foams by introducing hydrophobic-modified cellulose nanofibers. ACS Applied Materials and Interfaces, 9, 9250-9254 (2017).

https://doi.org/10.1021/acsami.7b01329

[19] Wang L., Hikima Y., Ohshima M., Yusa A., Yamamoto S., Goto H.: Unusual fabrication of lightweight injection-molded polypropylene foams by using air as the novel foaming agent. Industrial and Engineering Chemistry Research, 57, 3800-3804 (2018).

https://doi.org/10.1021/acs.iecr.7b05331

[20] Wang G., Zhao G., Wang S., Zhang L., Park C. B.: Injection-molded microcellular PLA/graphite nanocomposites with dramatically enhanced mechanical and electrical properties for ultra-efficient EMI shielding applications. Journal of Materials Chemistry C, 25, 6847-6859 (2018).

https://doi.org/10.1039/C8TC01326H 
[21] Shaayegan V., Wang C., Costa F., Han S., Park C. B.: Effect of the melt compressibility and the pressure drop rate on the cell-nucleation behavior in foam injection molding with mold opening. European Polymer Journal, 92, 314-325 (2017).

https://doi.org/10.1016/j.eurpolymj.2017.05.003

[22] Wu H., Zhao G., Wang G., Zhang W., Li Y.: A new coreback foam injection molding method with chemical blowing agents. Materials and Design, 144, 331-342 (2018). https://doi.org/10.1016/j.matdes.2018.02.043

[23] Ferrás L. L., Sitotaw Y. W., Fernandes C., Nóbrega J. M., Carneiro O. S.: A numerical and experimental study on weld lines formation and strength in extrusion. Polymer Engineering and Science, 58, 249-260 (2017).

https://doi.org/10.1002/pen.24551

[24] Pisipati R., Baird D. G.: Correlation of non-linear rheological properties of polymer melts with weld-line strength. in 'Polymer processing and properties' (eds.: Astarita G., Nicolais L.) Springer, Boston, 215-228 (1984). https://doi.org/10.1007/978-1-4613-2781-3 21

[25] Carneiro O. S., Ferrás L. L., Teixeira P., Fernandes C. P., Nóbrega J. M.: Weld lines in extrusion: Understanding the role of the flow conditions. AIP Conference Proceedings, 1662, 030012/1-030012/10 (2015). https://doi.org/10.1063/1.4918887

[26] Kitayama S., Tamada K., Takano M., Aiba S.: Numerical optimization of process parameters in plastic injection molding for minimizing weldlines and clamping force using conformal cooling channel. Journal of Manufacturing Processes, 32, 782-790 (2018). https://doi.org/10.1016/j.jmapro.2018.04.007

[27] Kalus J., Jørgensen J. K.: Measuring deformation and mechanical properties of weld lines in short fibre reinforced thermoplastics using digital image correlation. Polymer Testing, 36, 44-53 (2014).

https://doi.org/10.1016/j.polymertesting.2014.03.017

[28] Minh P. S., Do T. T., Uyen T. M. T., Nhan P. T.: A study on the welding line strength of composite parts with various venting systems in injection molding process. Key Engineering Materials, 737, 70-76 (2017).

https://doi.org/10.4028/www.scientific.net/KEM.737.70
[29] Zhou Y., Mallick P. K.: Effects of melt temperature and hold pressure on the tensile and fatigue properties of an injection molded talc-filled polypropylene. Polymer Engineering and Science, 45, 755-763 (2010). https://doi.org/10.1002/pen.20301

[30] Turng L-S., Kharbas H.: Effect of process conditions on the weld-line strength and microstructure of microcellular injection molded parts. Polymer Engineering and Science, 43, 157-168 (2003). https://doi.org/10.1002/pen.10013

[31] Kumar V., Suh N. P.: A process for making microcellular thermoplastic parts. Polymer Engineering and Science, 30, 1323-1329 (1990). https://doi.org/10.1002/pen.760302010

[32] Hou J., Zhao G., Wang G., Dong G., Xu J.: A novel gasassisted microcellular injection molding method for preparing lightweight foams with superior surface appearance and enhanced mechanical performance. Materials and Design, 127, 115-125 (2017).

https://doi.org/10.1016/j.matdes.2017.04.073

[33] Chen S-C., Hsu P-S., Hwang S-S.: The effects of gas counter pressure and mold temperature variation on the surface quality and morphology of the microcellular polystyrene foams. Journal of Applied Polymer Science, 127, 4769-4776 (2013). https://doi.org/10.1002/app.37994

[34] Wang G-L., Zhao G-Q., Wang J-C., Zhang L.: Research on formation mechanisms and control of external and inner bubble morphology in microcellular injection molding. Polymer Engineering and Science, 55, 807835 (2015).

https://doi.org/10.1002/pen.23948

[35] Spoerrer A. N. J., Bangarusampath D. S., Altstaedt V.: The challenge of foam injection-moulding - Possibilities to improve surface appearance, foam morphology and mechanical properties. Cellular Polymers, 27, 101121 (2008). https://doi.org/10.1177/026248930802700203 